\title{
Crop biotechnology for sustainable agriculture in the face of climate crisis
}

\author{
Ho Soo Kim ${ }^{1} \cdot$ Sang-Soo Kwak ${ }^{1}$
}

Published online: 30 March 2020

(c) Korean Society for Plant Biotechnology 2020

\section{Introduction}

A dramatic increase in the global population, combined with rapid industrialization in developing countries, has placed great strains on global food and energy supplies. According to United Nations (UN) Food and Agricultural Organization (FAO) estimates, the world population will exceed 9.7 billion in 2050 (FAO 2018), and approximately $57 \%$ of this population (5.5 billion people) will occupy Asia. If we continue to use energy and food resources at the current rate, we will need more than 3.5 times the current energy supply and 1.7 times the current food supply in 2050. In addition, climate change continually challenges our ability to feed the increasing global population. Agricultural production is extremely vulnerable to climate change, and its disruption will make it difficult to support the estimated world population in 2050. Thus, understanding how and to what extent climate change will affect agricultural productivity is crucial.

The UNs' 2030 Agenda for Sustainable Development targets the global scientific community for achieving the Sustainable Development Goals (SDGs) to ensure the future well-being of the planet. To end poverty and hunger and make human life inclusive, safe, resilient, and sustainable, it is essential to strengthen our ability to develop new improved cultivars using modern agricultural biotechnology (SDGs 2020). To cope with the global food and energy crises as well as environmental problems, the development of new industrial crop varieties suitable for cultivation on marginal lands is urgently needed. Moreover, to establish sustainable agriculture, it is important to critically investigate abiotic stress physiology of crop plants and functional

Sang-Soo Kwak

sskwak@kribb.re.kr

1 Plant Systems Engineering Research Center, Korea Research Institute of Bioscience and Biotechnology (KRIBB), 125 Gwahak-ro, Daejeon 34141, Korea genomics of useful target genes. Plant biotechnology can be used as a tool to maximize plant productivity by introducing stress tolerance genes and key metabolic genes from wild germplasm into environmentally adapted cultivars (Kwak 2019).

In November 2014, the InterAcademy Partnership (IAP) Board and Executive Committee agreed that food and nutrition security (FNS) is important and, therefore, pioneered a new series of IAP projects catering to this topic. The Association of Academies and Societies of Sciences in Asia (AASSA) Expert Working Group was established to address aspects of future FNS in the Asia-Pacific region, with respect to future population growth and projected regional trends related to both under-nutrition and over-nutrition. Reports on opportunities and challenges for research on food and nutrition security and agriculture (FNSA) in Asia were published in March 2018 (IAP 2018). In addition, the AASSA-Far Eastern Branch Russian Academy of Sciences (FEB RAS) Regional Workshop on "Climate Change Adaptation and Mitigation: Sustainable Agriculture and Health Security" was held in Birobidzhan, Russia during October 2-4, 2018 (Grigorieva 2018).

To cope with the global climate change via sustainable regional collaboration, the AASSA-Korean Academy of Sciences and Technology (KAST) Regional Workshop on "Crop Biotechnology for Sustainable Agriculture" was successfully organized recently. The objectives of this workshop were (1) to improve agriculture production, human health, and social security by strengthening research activities in the field of crop biotechnology; (2) to develop reliable and environmentally sustainable approaches for sustainable agriculture by increasing collaboration among scientists and experts; (3) to provide high-quality, evidence-based scientific advice that may be submitted to the concerned institutions/agencies in Asia and other regions. 


\section{AASSA-KAST regional workshop on crop biotechnology for sustainable agriculture}

The AASSA-KAST Regional Workshop on "Crop Biotechnology for Sustainable Agriculture" was held in Seoul, Korea, during September 23-25, 2019 (AASSA-KAST 2019). This workshop was co-organized by the KAST and AASSA. A total of 18 lectures were presented by leading experts, of which 11 were presented by international speakers and seven by Korean speakers. The international speakers represented ten countries including Philippines (two speakers), China, Japan, Indonesia, Kazakhstan, Nepal, Pakistan, Sri Lanka, Turkey, and Russia (one speaker each). In addition to speakers, this workshop was attended by approximately 50 participants including university faculty members, researchers, postgraduate students, heads of scientific organizations, policy-makers, and other stakeholders. In addition to lectures and the AASSA Executive Board Meeting, a 1-day technical tour was carried out at the Agricultural Science Hall, National Institute of Crop Science and National Institute of Agricultural Sciences, Rural Development Administration at Jeonju, Korea to understand the current status of agricultural research and development (R\&D) in Korea and promote collaboration among AASSA member countries.

\section{Recommendations of the AASSA-KAST regional workshop}

Through the AASSA-KAST Regional Workshop, we gained a common understanding of the importance of modern crop biotechnology in developing biotech crops for sustainable food and health security in the face of climate change, as per the following recommendations: (1) modern biotechnology, integrated with traditional agricultural technology, is important in solving global food, energy, environmental, and health problems; (2) plant scientists play a key role and share the responsibility to cope with the abovementioned global issues; (3) development of ecological and human friendly genetically modified (GM) crops is critical in the face of climate change; (4) new breeding technologies (NBTs) including genome editing should be continuously developed to generate new crops for achieving FNS; (5) regional collaborations are very important for trustfully sharing the technology, know-how, and experiences among countries involved in international collaboration; (6) continuous regional workshops on agricultural biotechnology are required to ensure sustainable FNS at the regional level. A special issue on the AASSAKAST Regional Workshop will be published in "Plant
Biotechnology Reports", a peer-reviewed international journal published by Springer, in April 2020.

In this special issue, 12 articles (ten review articles and two original articles) were invited among 18 presentations at the AASSA-KAST Regional Workshop. Articles on plant science mainly describe molecular breeding of crops for improving tolerance to abiotic stresses such as drought, salinity, and oxidative stress. Articles in the area of plant biotechnology focus on rice, sweet potato, cassava, and buckwheat for sustainable food security. Shinwari et al. (2020) reviewed genetic engineering approaches for the development of genotypes with enhanced tolerance to drought stress. Ali and Yun (2020) reviewed the role of Arabidopsis HOS15 in negatively regulating abscisic acid (ABA) signaling and drought stress tolerance. Akyol et al. (2020) reviewed novel insights into the root microbiome of halophytes to improve salinity tolerance in crops. Li et al. (2020) reviewed dryland agriculture for sustainable productivity in China. Manangkil et al. (2020) discussed the role of biotechnology in rice molecular breeding in the Philippines. Mo and Jeung (2020) reviewed the floury endosperm mutants for dry-milling rice cultivars. Sukara et al. (2020) reviewed the status of agriculture and value-added cassava in Indonesia. Kim et al. (2020) reported the metabolic engineering of low molecular weight antioxidants in sweet potato to ensure sustainable FNS. Borovayaa and Klykova (2020) reviewed the biosynthesis and accumulation of flavonoids in buckwheat. Zhambakin and Zhapar (2020) reported the national status and prospects of plant biotechnology in Kazakhstan. Among the original articles, Paeng et al. (2020) described the function of the molecular chaperone NPR1 in protecting Arabidopsis plants from heat stress, while Demican et al. (2020) described a mitochondrial alternative oxidase (AOX1a), which is required for the mitigation of arsenic-induced oxidative stress in Arabidopsis.

Acknowledgements We thank all researchers who contributed to the special issue. We also thank the Korean Academy of Science and Technology (KAST) and the Association of Academies and Societies of Sciences in Asia (AASSA) for supporting the AASSA-KAST Regional Workshop on "Crop Biotechnology for Sustainable Agriculture". This work was supported by the Korean Institute of Planning and Evaluation for Technology in Food, Agriculture, Forestry (IPET) through the Agri-Bio Industry Technology Development Program funded by the Ministry of Agriculture, Food and Rural Affairs (MAFRA) (118038-3).

\section{References}

AASSA-KAST (2019) Abstract book on AASSA-KAST Regional Workshop: Crop biotechnology for sustainable agriculture (23-25 September, Seoul, Republic of Korea), pp 1-63

Akyol TY, Sato S, Turkan I (2020) Deploying root microbiome of halophytes to improve salinity tolerance of crops. Plant Biotechnol Rep. https://doi.org/10.1007/s11816-020-00594-w 
Ali A, Yun DJ (2020) Arabidopsis HOS15 is a multifunctional protein that negatively regulate ABA-signaling and drought stress. Plant Biotechnol Rep. https://doi.org/10.1007/s11816-020-00600-1

Borovayaa SA, Klykova AG (2020) Some aspects of biosynthesis and accumulation of flavonoids in buckwheat. Plant Biotechnol Rep. https://doi.org/10.1007/s11816-020-00614-9

Demican N, Cucun G, Uzilday B (2020) Mitochondrial alternative oxidase (AOX1a) is required for mitigation of arsenic induced oxidative stress in Arabidopsis thaliana. Plant Biotechnol Rep. https://doi.org/10.1007/s11816-020-00595-9

FAO (2018) The future of food and agriculture: alternative pathways to 2050. Food and Agriculture Organization of the United Nations, Rome. https://www.fao.org/global-perspectivestudies/resources/ detail/en/c/1157074/

Grigorieva EA (2018) Foreword. For the 'Regional Problems' special issue on "Climate change adaptation and mitigation: sustainable and health security" (01-05 October, Birobidzhan, Russian Federation). Regional Probl 21:7-8

IAP (2018) Opportunities and challenges for research on food and nutrition security and agriculture in Asia, pp 1-59

Kim HS, Wang W, Kang L, Kim SE, Lee CJ, Park SC, Park WS, Ahn MJ, Kwak SS (2020) Metabolic engineering of low molecular weight antioxidants in sweetpotao. Plant Biotechnol Rep. https:// link.springer.com/article/10.1007/s11816-020-00621-w

Kwak SS (2019) Biotechnology of the sweetpotato: ensuring global food and nutrition security in the face of climate change. Plant Cell Rep 38:1361-1363

Li GX, Xu BC, Yin LN, Wang SW, Zhang SQ, Shan L, Kwak SS, Ke Q, Deng XP (2020) Dryland agricultural environment and sustainable productivity. Plant Biotechnol Rep. https://doi.org/10.1007/ s11816-020-00613-w
Manangkil OE, Abdula SE, Quilang EJP (2020) Role of biotechnology in rice breeding strategy of the Philippines. Plant Biotechnol Rep. https://doi.org/10.1007/s11816-020-00618-5

Mo Y, Jeung JU (2020) The use of floury endosperm mutants to develop rice cultivars suitable for dry milling. Plant Biotechnol Rep. https://doi.org/10.1007/s11816-020-00604-x

Paeng SK, Chi YH, Kang CH, Chae HB, Lee ES, Park JH, Wi SD, Bae SB, Phan KAT, Lee SY (2020) Chaperone function of Arabidopsis NPR1. Plant Biotechnol Rep. https://doi.org/10.1007/s1181 6-020-00609-6

SDGs (2020) About the sustainable development goals. https://www. un.org/sustainabledevelopment/sustainable-development-goals/

Shinwari ZK, Jan SA, Nakashima K, Yamaguchi-Shinozaki K (2020) Genetic engineering approaches to understanding drought tolerance in plants. Plant Biotechnol Rep. https://doi.org/10.1007/ s11816-020-00598-6

Sukara E, Hartati S, Ragamustari SK (2020) State of the art of Indonesian agriculture and the introduction of innovation for added value of cassava. Plant Biotechnol Rep. https://doi.org/10.1007/ s11816-020-00605-w

Zhambakin K, Zhapar K (2020) Current status and prospects of plant biotechnology in Kazakhstan. Plant Biotechnol Rep. https://doi. org/10.1007/s11816-020-00601-0

Publisher's Note Springer Nature remains neutral with regard to jurisdictional claims in published maps and institutional affiliations. 